\title{
Experimental study on the thermal behaviour of fire exposed slim- floor beams
}

\author{
V. Albero ${ }^{a^{*}}$, A. Espinós ${ }^{a}$, E. Serra ${ }^{a}$, M. L. Romero a and A. Hospitaler ${ }^{a}$ \\ aCITECH, Universitat Politècnica de València, Spain \\ *corresponding author, e-mail address: valbero@mes.upv.es
}

\begin{abstract}
Steel-concrete composite beams embedded in floors (slim-floors) offer various advantages such as the floor thickness reduction or the ease of installation of under-floor technical equipment. However, this typology presents important differences in terms of thermal behaviour, as compared to other composite beams, when exposed to elevated temperatures. These differences are due to their special configuration, being totally contained within the concrete floor depth. Moreover, the current European fire design code for composite steelconcrete structures (EN 1994-1-2) does not provide any simplified thermal model to evaluate the temperature evolution of each slim-floor part during a fire. Additionally, only a few experimental studies can be found which may help understand the thermal behaviour of these composite beams.

This paper presents an experimental investigation on the thermal behaviour of slim-floor beams. Electrical radiative panels were used in the test setup to produce the thermal heating. The thermal gap between the lower flange of the steel profile and the bottom steel plate was studied, being found to be one of the most influential elements over the cross-section temperature gradient. The experimental campaign was developed by varying the crosssection configuration in order to evaluate the influence of this parameter over the slim-floor thermal behavior. Finally, the experiments carried out were used to develop and calibrate a finite element thermal model which may help in further research on the thermal behaviour of slim-floor composite beams.
\end{abstract}

Keywords: Composite steel-concrete beams, fire resistance, slim-floors, thermal behaviour.

\section{Introduction}

Composite steel-concrete beams embedded in floors (slim-floors) are being increasingly used in residential and non-residential buildings given its suitability to be totally contained within the depth of the concrete floor. Therefore, this composite beam solution offers various advantages like the floor thickness reduction, the possibility of incorporating under-floor technical equipment and the increase of working space.

Related to the fire design, a suitable behaviour of the slim-floor in the event of fire is expected. This enhanced performance is based on being exposed to fire only from the lower flange, in contrast with other composite beams, which are not totally embedded in the concrete floor. Besides, EN 1994-1-2 [1] provides simplified models to evaluate the temperatures due to standard fire for composite beams without concrete encasement (EN 1994-1-2 Clause 4.3.4.2.2) and composite beams with partial encasement (EN 1994-1-2 Annex F). However, simplified models to evaluate temperatures in fire for composite beams embedded in floors (slim-floors) are not available in standards. Therefore, specific advanced models are required.

Apart from standards, Zaharia and Franssen [2] developed simple equations for the calculation of temperatures within the crosssection of a specific slim-floor called Integrated Floor Beam (IFB) under ISO-834 standard fire. IFB is an asymmetric I-section built from a cut hot-rolled symmetric I-section welded to a plate. This simple model was developed from an 
advanced finite element model validated with tests. It provides equations to obtain the temperature in the bottom flange or plate, web and reinforcing bars embedded in concrete. Top flange temperature is not provided because it does not reach $400{ }^{\circ} \mathrm{C}$ before 120 minutes of ISO-834 fire exposure, retaining its full strength. A comparison of this simplified model against other models provided by standards for composite beams with partial or no concrete encasement was carried out by Cajot et al. [3] and Romero et al. [4].

The work presented hereafter is focused on other slim-floor configuration called Shallow Floor Beam (SFB). SFBs are built from a hotrolled symmetric I-section welded (without cutting) to a lower plate. SFBs show a better thermal behaviour than IFBs due to the air gap, which appears between the SFB lower flange and the bottom plate. Significant temperature differences between the bottom plate and lower flange on SFB composite beams was observed experimentally by Newman [5]. The described air gap is the main difference between SFB and IFB slim-floor configuration. Other research work developed by Fellinger and Twilt [6] suggested that this air gap should be ensured through the SFB production process to increase the slim-floor fire resistance in practice.

In this work, an experimental campaign is presented by varying the cross-section configuration in order to evaluate the influence of this parameter over the slim-floor thermal behaviour. The experimental results are also used to develop and calibrate a finite element thermal model which may help in further research on the thermal behaviour on these composite beams.

\section{Experimental campaign}

The experimental campaign was performed in the testing facilities of ICITECH (Concrete Science and Technology Institute) at UPV Valencia, Spain. In this experimental program, an electrical radiative furnace was used. The test set up allowed for the fire exposure of the specimen only from its lower surface, see Fig. 1. This configuration matches with the real exposure of slim-floor beams in practical situations.

The radiative panels used reach $800^{\circ} \mathrm{C}$ inside the furnace.
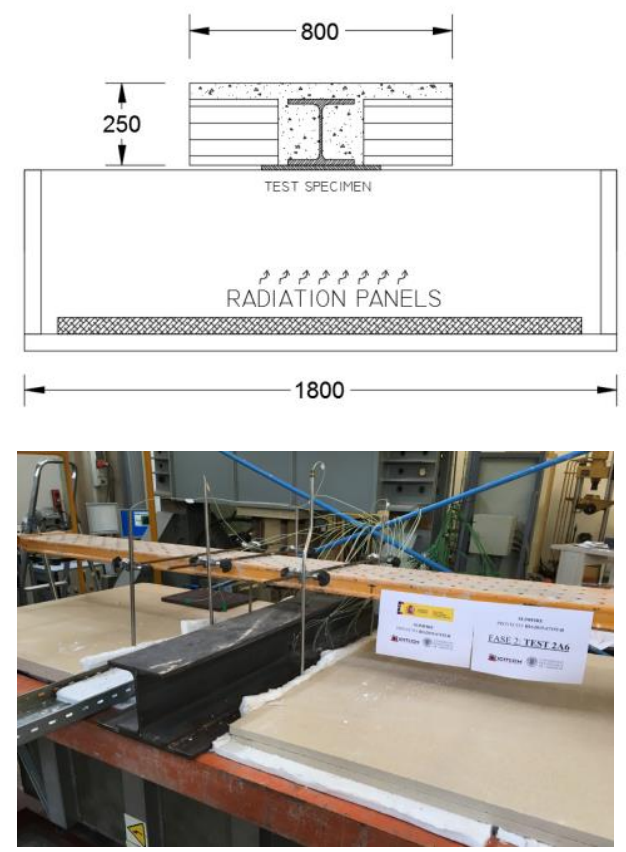

Fig. 1. Experimental test set up.

The main objective of this experimental campaign is to obtain a better understanding of the thermal behaviour of slim-floor beams and investigate the influence of different parameters over their fire performance. . In order to accomplish these objectives, different specimens were tested (see Table 1).

Table 1. Experimental campaign.

\begin{tabular}{cc}
\hline Exp. ID & Description \\
\hline A1 & HEB200+Plate15 \\
A2 & HEB200+Plate15+NormalConcrete \\
A3 & IFB+NormalConcrete \\
\hline
\end{tabular}

Specimen A1 was built from a hot rolled HEB200 beam welded to a lower plate of dimensions $360 \times 15 \mathrm{~mm}$. This case was tested without concrete infill in order to focus on the validation of the thermal contact between the bottom plate and lower flange. However, specimen A2 was defined as the previous one but including a precast hollow core slab of $20 \mathrm{~cm}$ height in the transverse direction, concrete encasement and $2 \phi 20 \mathrm{~mm}$ reinforcing bars (see Fig. 2). Finally, specimen A3 was made from a $1 / 2$ IPE450 welded to a lower plate of $360 \times 30$ $\mathrm{mm}$. The thickness of this lower plate has been set in such a way that it equals the sum of the bottom plate plus lower flange thickness from specimen $\mathrm{A} 2(15+15 \mathrm{~mm})$. This last test was carried out to provide evidences about the different thermal behaviour between SFB and 
IFB due to the thermal contact resistance in the gap between bottom plate and lower flange.

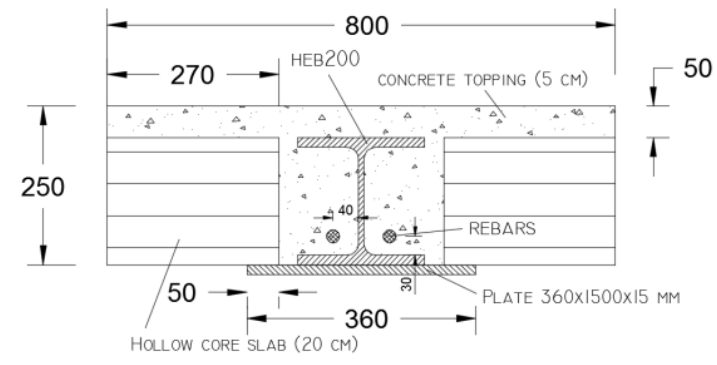

Fig. 2. A2 specimen dimensions.

In order to evaluate the thermal behaviour of each specimen, up to 17 thermocouples were installed in the cross-section (see Fig. 3). This configuration allows for an exhaustive analysis of the temperature evolution of each crosssection element: bottom plate, lower and upper flange, profile web, reinforcing bars, etc.

a) Specimen A1

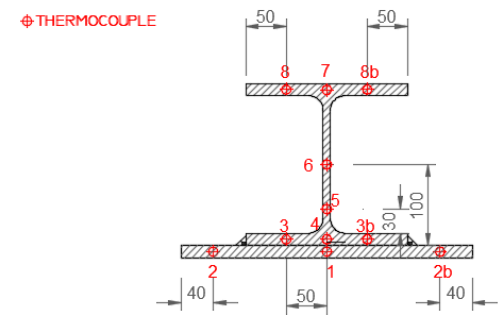

b) Specimen $\mathrm{A} 2$

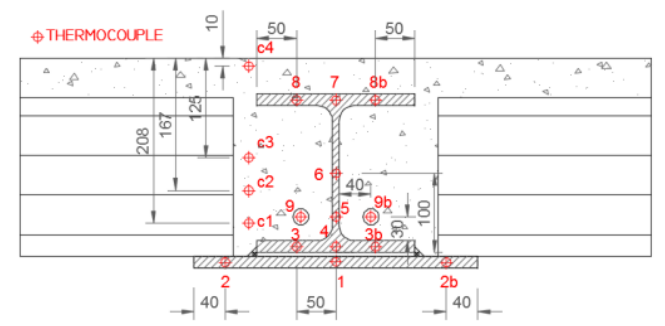

c) Specimen A3

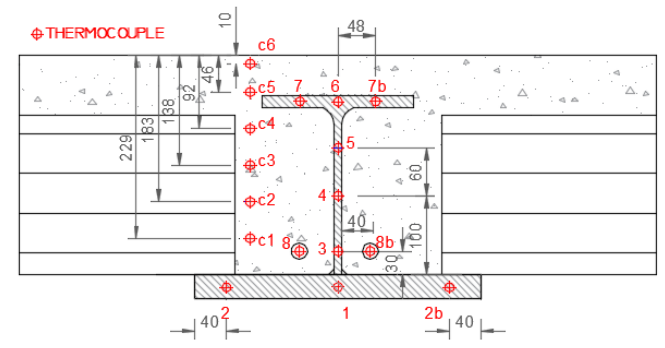

Fig. 3. Thermocouple distribution.

\section{Numerical model}

A finite element thermal model for simulating nonlinear heat transfer analysis along the slim-floor beam was developed by employing the general purpose finite element package ABAQUS [8]. The cross-section was meshed with four-noded quadrilateral elements, see Fig. 4. The mesh density was controlled to have a maximum element size of $2.5 \mathrm{~mm}$, what proved to be sufficient to predict accurately the temperature along the cross-section.

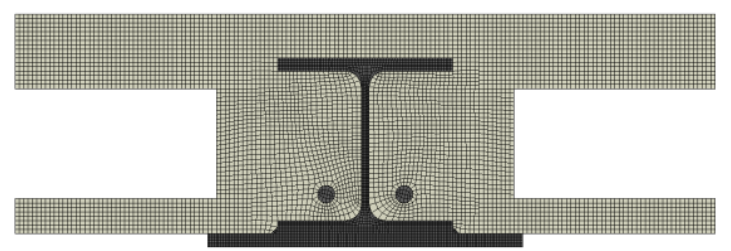

Fig. 4. Numerical model.

The slim-floor cross-section was only exposed to fire from its lower surface, matching with the electrical furnace setup and real fire exposure conditions of slim-floor beams in practical situations.

The values recommended in EN 1991-1-2 [9] were adopted for the governing parameters of the heat transfer problem. A constant convective coefficient of $25 \mathrm{~W} / \mathrm{m}^{2} \mathrm{~K}$ was assumed for the exposed surface, while $4 \mathrm{~W} / \mathrm{m}^{2} \mathrm{~K}$ was applied in the unexposed surface. Heat radiation was taken into account separately. Related to the radiative heat flux, an emissivity value of 0.7 was used for steel and concrete surfaces. Besides, cavity radiation was assumed in the hollow core slab holes.

One of the essential parts of the thermal model is the thermal contact resistance between each cross-section part. These contacts have a significant influence in the temperature evolution along the slim-floor section. Specifically, the thermal resistance at the boundary between the lower flange and the bottom plate was modelled through a constant gap conductance value of $100 \mathrm{~W} / \mathrm{m}^{2} \mathrm{~K}$. Moreover, a gap radiation was also considered following the suggestions by other authors [6], [7], who claimed that a thermal bowing may appear between both elements. In turn, at the boundary surface between the steel profile and concrete infill or bottom plate and hollow core slab, a gap conductance value of $250 \mathrm{~W} / \mathrm{m}^{2} \mathrm{~K}$ was considered. In this case no gap radiation was assumed.

This numerical model took into account the temperature dependent thermal properties of steel and concrete. For this purpose, the 
formulation of the material properties (conductivity and specific heat) as a function of the temperature from EN 1994-1-2 [1] were used.

\section{Model validation}

The previously described finite element thermal model was validated using the specimens A1, A2 and A3. For the sake of simplicity, only the steel profile thermocouples are showed in the following validation figures. The temperature evolution along the steel members is shown (bottom steel plate, steel profile and reinforcing bars), which has a strong influence in the bending capacity of the composite beam at elevated temperatures.

The first validation, using A1 specimen - see Fig. 5 -, was performed to validate the thermal contact between the bottom steel plate and lower flange (steel-steel) as no concrete elements were used. In this case, a value of $100 \mathrm{~W} / \mathrm{m}^{2} \mathrm{~K}$ for the thermal conductance was used, besides thermal radiation was accounted for in the gap. This assumption matched well with the experimental results, see Fig. 5.

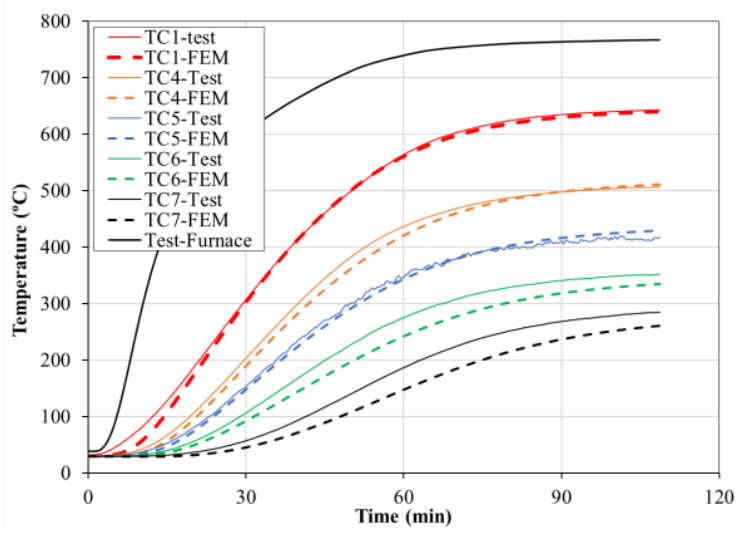

Fig. 5. A1 specimen validation.

The second specimen, A2, was used to calibrate the gap conductance value of 250 $\mathrm{W} / \mathrm{m}^{2} \mathrm{~K}$ for the thermal interaction between steel-concrete surfaces, while maintaining the steel-steel interaction definition. In concretesteel interaction, no thermal radiation was considered. The model also shows an accurate behaviour for the temperature evolution of bottom steel plate (TC1), lower flange (TC4) and reinforcing bars (TC9), see Fig. 6.

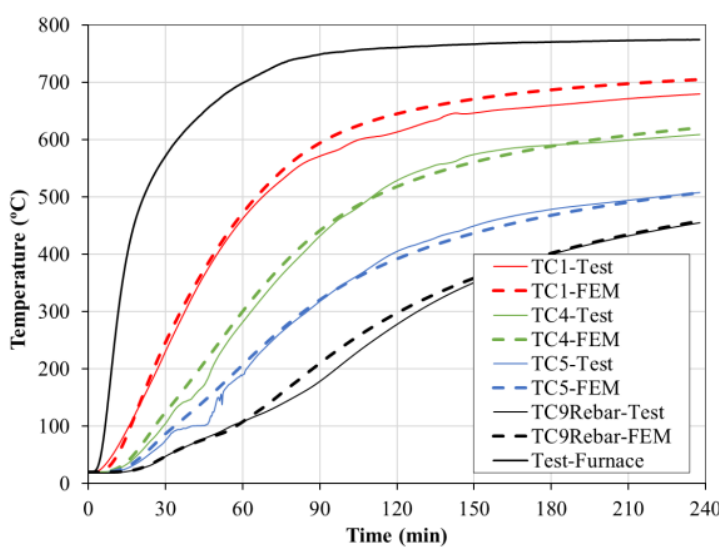

Fig. 6. A2 specimen validation.

Finally, the numerical model was used to simulate the IFB configuration (specimen A3). In this case, no lower steel flange was considered. Again, accurate results were achieved for the bottom plate (TC1), upper steel flange (TC6) and reinforcing bars (TC8), see Fig. 7.

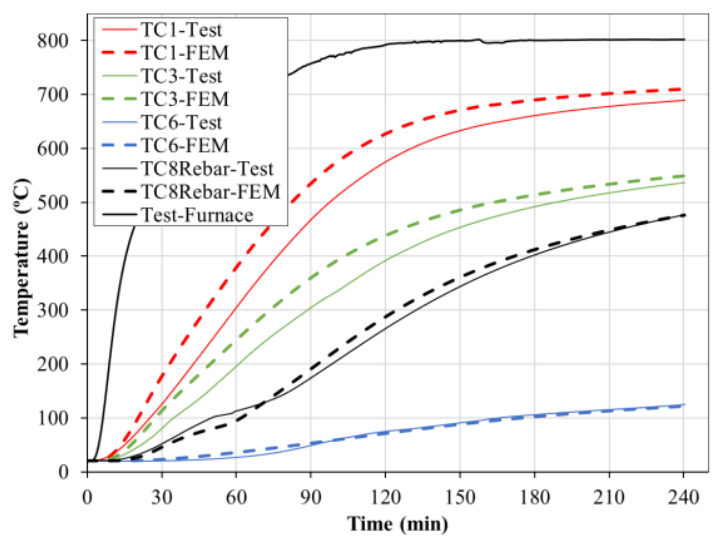

Fig. 7. A3 specimen validation.

\section{Comparison of the thermal performance}

Once the numerical model was validated, the SFB and IFB configurations were exposed to standard fire ISO834 model. Thus, the temperature field along the slim-floor crosssection was obtained for different fire standard exposure times. Fig. 8 shows the temperature field for $120 \mathrm{~min}$ of fire exposure. Besides, it can be also observed in Fig. 9 that while IFB bottom plate achieves $940{ }^{\circ} \mathrm{C}$ at 120 minutes of fire exposure, the lower flange of SFB steel profile reaches $825^{\circ} \mathrm{C}$ thanks to the thermal gap between steel members. In this case, the temperature difference between SFB bottom plate and lower steel flange is higher than $100{ }^{\circ} \mathrm{C}$ 
(960-825 $\left.{ }^{\circ} \mathrm{C}\right)$. It demonstrates the important influence of the thermal gap.

a) SFB

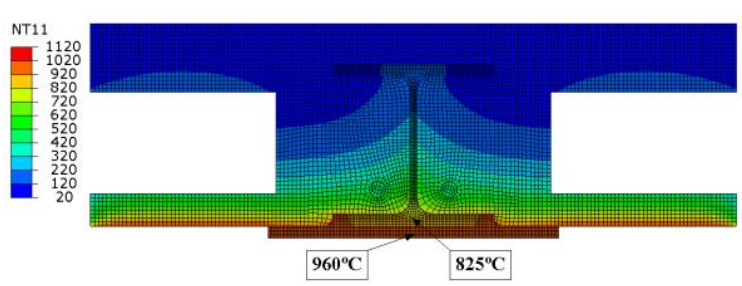

b) IFB

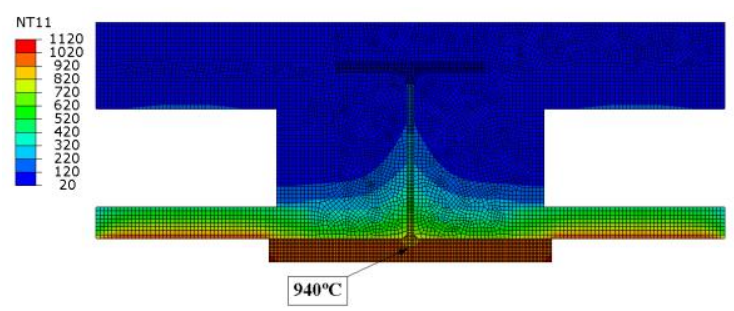

Fig. 8. Temperature field at 120 minutes of ISO834 fire exposure

Finally, Fig. 9 shows the temperature evolution, for any exposure time, of the IFB bottom plate and the SFB lower flange. It can be observed that due to the thermal gap in SFB, the temperature difference is maintained around $100-120^{\circ} \mathrm{C}$ but it shows a slowly decrease at elevated exposure times caused by thermal inertia.

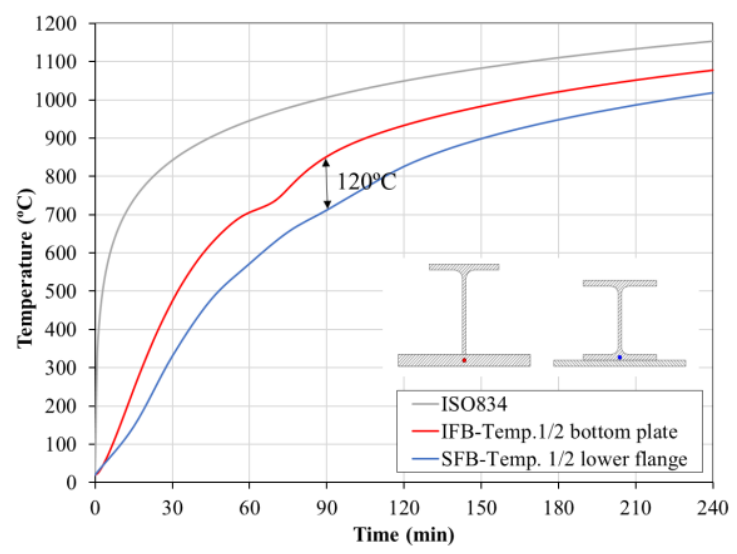

Fig. 9. Comparison of the temperature evolution in lower steel plate-flange

\section{Conclusions}

In conclusion, the experimental campaign carried out in this work has shown the important influence of the thermal gap between bottom plate and steel profile lower flange over the temperature evolution along the cross-section of SFB.

The particular behavior observed in SFB may be beneficial for the fire resistance of slim-floor beams.

Additionally, this works presented a validated advanced thermal model which may be useful for further analysis of this composite cross-section type.

\section{References}

[1] CEN. European Committee for Standardization. EN 1994-1-2, Eurocode 4. Design of composite steel and concrete structures - Part 1-2: General rules - Structural fire design. Brussels; 2005.

[2] Zaharia R, Franssen JM. Simple equations for the calculation of the temperature within the crosssection of slim floor beams under ISO Fire. Steel and Composite Structures 2012; 13(2):171-185.

[3] Cajot LG, Gallois L, Debruyckere R, Franssen JM. Simplified design method for slim floor beams exposed to fire. Nordic Steel Construction Conference 2012. Oslo, Norway.

[4] Romero ML, Cajot LG, Conan Y, Braun M. Fire design methods for slim-floor structures. Steel Construction 2015; 8(2):102-109.

[5] Newman GM. Fire resistance of slim floor beams. Journal of Constructional Steel Research 1995; 33(1-2):87-100.

[6] Fellinger JHH, Twilt T. Fire resistance of slim floor beams. Proceedings of the 2nd ASCE Conference. Irsee, Germany; 1996.

[7] Both C, Fellinger JHH, Twilt L. Shallow floor construction with deep composite deck: From fire tests to simple calculation rules. Heron. 1997;42: 145-58.

[8] ABAQUS. ABAQUS/standard version 6.14 user's manual: volumnes I-III. Pawtucket, Rhode Island: Hibbit, Karlsson \& Sorenson, Inc.

[9] CEN. European Committee for Standardization. EN 1991-1-2, Eurocode 1: Actions on structures. Part 1-2. General actions - actions on structures exposed to fire. Brussels; 2002. 